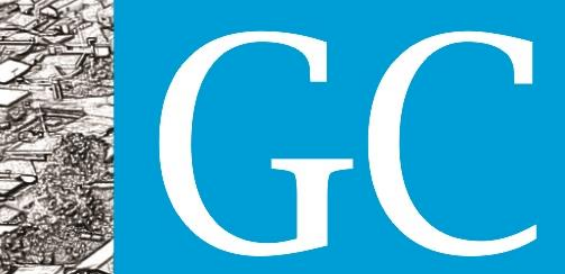

Revista Nacional de

Gerenciamento de Cidades

National Joumal of Cities Management

\title{
Evolução das paisagens do Parque Municipal Nascentes do Belém e arredores (Curitiba-PR)
}

Evolution of the landscapes of the Parque Municpal Nascente do Belém and surroundings (Curitiba-PR)

Evolución de los paisajes del Parque Municpal Nascente do Belém y alrededores (Curitiba-PR)

Janete Lúcia Conci

Mestre em Tecnologia e Desenvolvimento pela Universidade Tecnológica Federal do Paraná (UTFPR)

Helena Mendonça Faria

Profa Adj. da Universidade Federal do Paraná- Departamento de Geografia (DGEOG-UFPR)

João Carlos Nucci

Prof. Associado III do Departamento de Geografia da Universidade Federal do Paraná (DGEOG-UFPR)

Oriana Aparecida Fávero

Profa Dra das Universidades Presbiteriana Mackenzie (UPM) e São Judas Tadeu (USJT) 


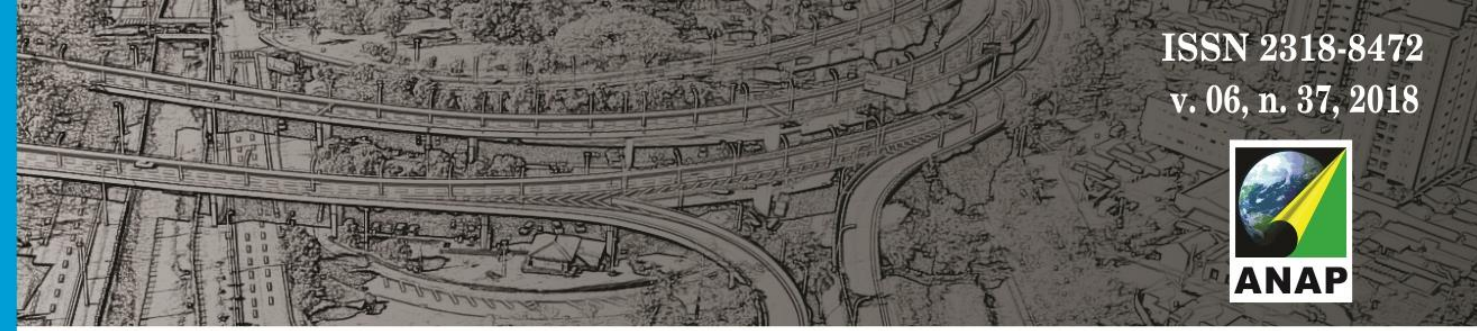

Gerenciamento de Cidades

\section{RESUMO}

O Belém é um importante rio do município de Curitiba cujas nascentes se encontram em área de urbanização ocorrida principalmente entre as décadas de 1960 e 1980. O Parque Municipal Nascentes do Belém, implantado em 2001, tem levantado suspeitas sobre sua efetividade como unidade de conservação da natureza, despertando interesse sobre sua história de criação. Assim, realizou-se um estudo de evolução das paisagens entre os anos de 1952 e 2001 do parque e de seus arredores, abordando questões relativas à ocupação do solo urbano e à proteção ambiental. Foram realizadas pesquisas bibliográficas, cartográficas, trabalhos de campo, coletas de informações baseadas em fotografias aéreas que retratam partes de um período de 47 anos (1952-1999) e nas leis de zoneamento do município dos anos 1965, 1975, 2000 e 2015, além de entrevistas com técnicos da Prefeitura de Curitiba e com moradores dos bairros próximos ao parque. Constatou-se que, apesar das evidencias explícitas nas fotografias aéreas de posse dos órgãos públicos, não foram tomadas medidas eficientes de proteção ambiental e a área encontra-se ambientalmente degradada, com ocupações sem regularização, com um cemitério próximo às nascentes e um parque que cumpre apenas parcialmente funções de conservação da natureza. A ocupação da área evidenciou conflitos comuns às áreas urbanas brasileiras, onde se verifica em uma mesma porção de território: demandas por habitação, interesses construtivos e econômicos, e a necessidade de conservação ambiental.

Palavras-chave: análise temporal; meio ambiente; conflitos sociais e ambientais.

\section{ABSTRACT}

Belém is an important river in the municipal district of Curitiba whose source is located in an urban area developed mainly between the decades of 1960 and 1980, presenting social and environmental problems to current days. There are doubts about the effectiveness of the Belém Sources Municipal Park, created in 2001, as a nature conservation unit foreseen by a municipal law, rising interest about its creation history. Therefore, a study of the landscape evolution of the park and its surroundings between the years of 1952 and 2001 was done, covering issues relative to the occupation of urban land and environmental protection. Bibliographical and cartographic research were done as well as field work, information collection based on aerial photographs portraying parts of a 47 years (1952 -1999) period, and from the zoning by-laws of the municipal district from the years 1965, 1975, 2000 and 2015 , besides interviews with Curitiba Municipality technicians and residents of the park neighborhoods. In spite of the explicit evidence in the aerial photographs in the hands of the authorities, we realized that no efficient measures of environmental protection were taken and the area is environmentally degraded, with clandestine occupations with no zoning plan and a cemetery close to the source and a park that barely performs the role of a nature conservation unit. The history of the occupation of that area highlighted conflicts that are common in Brazilian urban areas, where the demands for homes, the construction and economic interests, and the environmental conservation need co-exist in a same territory portion.

Key words: Time analysis; environment; social and environmental conflicts.

\section{Resumen)}

El Belén es un río importante en la ciudad de Curitiba, cuyas fuentes se encuentran en zona urbana desde los años 1960 y 1980 . El Parque Municipal Nascentes del Rio Belém, establecido en 2001, ha levantado sospechas sobre su eficacia como unidad de conservación de la naturaleza, despertando el interés por su historia de la creación. Por lo tanto, se hizo un estudio de la evolución de los paisajes entre los años 1952 y 2001 el parque y sus alrededores con la intención de abordar las cuestiones relacionadas con el uso del suelo urbano y la protección del medio ambiente. Se realizaron búsquedas en la literatura, cartográfica, el trabajo de campo, recopilación de información basado en fotografías aéreas que muestran partes de un período de 47 años (1952-1999). También se consultó a las leyes de zonificación de la ciudad de los años 1965, 1975, 2000 y 2015, y también a cabo entrevistas con los técnicos de Curitiba y con los residentes de los barrios cercanos al parque. Se encontró que, a pesar de la evidencia explícita en las fotografías aéreas en poder de los organismos públicos, no se tomaron medidas efectivas de protección ambiental. La zona se degrada el medio ambiente, con ocupaciones sin regularización, con un cementerio cerca de las fuentes y un parque que cumpla sólo parcialmente las funciones de conservación de la naturaleza. La historia de la ocupación de la zona indicó conflictos comunes a las áreas urbanas de Brasil, donde se insertan la demanda de viviendas, la construcción y los intereses económicos, y la necesidad de conservación del medio ambiente en la misma porción de territorio.

Palabras clave: análisis temporal; medio ambiente; conflictos sociales y ambientales. 


\section{INTRODUÇÃO}

No planejamento territorial, a escolha de áreas merecedoras de proteção geralmente recai sobre padrões no território que permitam a manutenção da vida e dos inúmeros serviços ambientais tais como a manutenção e depuração de corpos hídricos, contenção de encostas, controle de cheias, purificação atmosférica, proteção da fauna e flora, além de benefícios sociais como a oferta de áreas de lazer, espaços educativos e de convivência e de melhora do conforto ambiental através do controle microclimático, entre outros.

No Brasil, há exemplos de criação legal de áreas a serem protegidas desde as primeiras décadas de 1800, porém, mais recentemente, destacam-se como leis federais protetoras de áreas de interesse o Código Florestal (1934, 1965 e 2012) e a lei que no ano 2000 criou o Sistema Nacional de Unidades de Conservação da Natureza (SNUC). Todavia, essas áreas destinadas à conservação da natureza sofrem pressões de diversos tipos, principalmente quando se encontram em área urbana, pois, segundo Maricato (2002), a construção da paisagem urbana é o reflexo das relações sociais e das disputas pela terra.

As Áreas de Preservação Permanente (APPs), previstas na Lei no 12.651 de 2012, têm sido ocupadas por uma população que não tem acesso à moradia, vindo a se instalar em áreas públicas e frágeis do ponto de vista ambiental. Além desse tipo de ocupação, as APPs são desrespeitadas em prol de empreendimentos imobiliários e áreas industriais regulares ou irregulares. Apesar dessas questões serem tratadas em leis, inclusive nas de zoneamento urbano, ainda se observa grande disparidade entre a legislação e a sua aplicação, como afirma Felicio (2007).

Os parques urbanos, podem ser considerados Unidades de Conservação, desde que cumpram as diretrizes da Lei 9.985/2000. Os parques urbanos, nascidos no final do século XIX, com a industrialização e consequente aumento da urbanização foram criados primeiramente para as elites e depois ganharam destaque como elemento urbano de recreação de massa (Macedo e Sakata, 2003). Representam os reflexos da ideia de conservação ambiental do homem moderno, que não sabendo lidar com a natureza a preserva em espaços intocados para contatos esporádicos, ou como um mínimo necessário à sobrevivência (Diegues,2008). Entretanto, desde o século XX o papel dos parques urbanos tem sido revisto no sentido de que há mais a ser aproveitado dos serviços ambientais que esses espaços prestam às populações urbanas, além de seu benefício como espaço de recreação. Isso se reafirma quando se liga a criação de áreas protegidas destinadas à conservação de mananciais e também em iniciativas de criação de corredores ecológicos e parques lineares, tendo como objetivo a ampliação de os benefícios gerados por áreas protegidas à qualidade ambiental urbana (FRANCIS e CHADWICK, 2013).

Mesmo com a existência de leis, o planejamento urbano e seus instrumentos, tais como o Plano Diretor no Brasil, são frutos de relações políticas e sociais e por isso se efetivam na medida em que são legitimados por grupos sociais, que são os atores da vida urbana. Para Oliveira (2014) a trajetória de um plano diretor de urbanismo pode ser dividida em três fases: elaboração, legitimação e implementação. Cada uma delas apresenta problemas e vicissitudes peculiares. Na fase de elaboração é importante perceber como o problema foi reconhecido e que tipo de solução foi encontrada. A resposta obtida deve ser objeto de um consenso, previamente a sua implementação, o qual pode ser amplo ou restrito, tratando-se da fase de legitimação. Finalmente, cabe implementar a política escolhida, o que certamente coloca questões de ordem material (isto é, obtenção dos recursos materiais e humanos necessários, adaptação da estrutura administrativa pré-existente), mas também pode recolocar objeções com relação à legitimidade da proposta (principalmente se o consenso em torno dela for fraco).

O Parque Municipal Nascentes do Belém é um parque urbano pertencente ao município de Curitiba, considerado pela Prefeitura como Unidade de Conservação, segundo o Sistema Municipal de Unidades de Conservação (CURITIBA, 2000). Porém, Misael e Nucci (2015), em uma avaliação do parque constataram a presença de vários problemas relacionados aos objetivos de uma unidade de conservação, tais como, área muito pequena, baixa diversidade de ambientes, edificações e construções ocupando boa parte dos espaços 


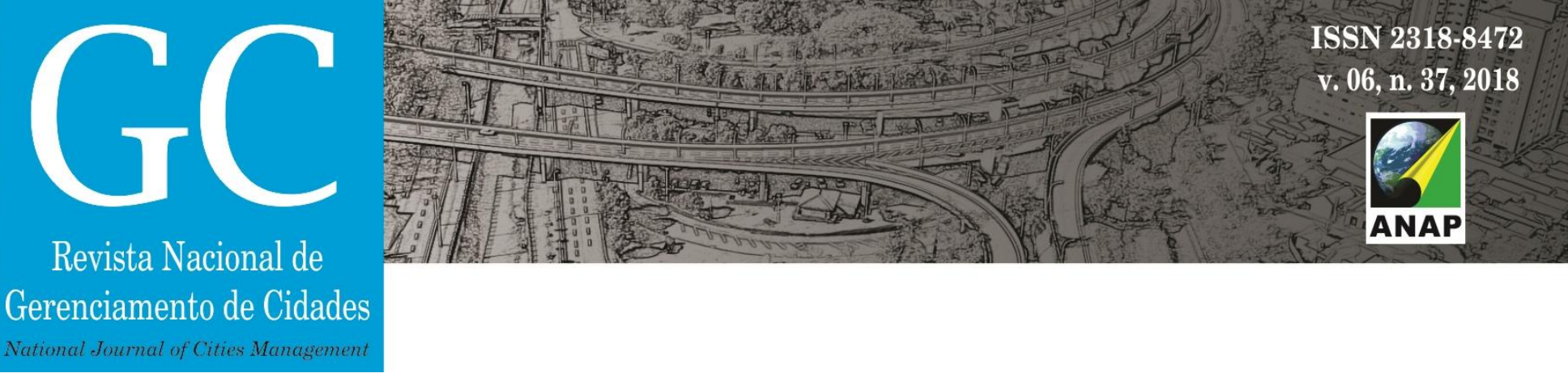

de cobertura vegetal, tais como "reflorestamento com bracatinga", "capoeira", "terrenos de cultura", "cultura efetiva e pomares" e, perto da linha do trem, uma pequena mancha classificada como "área urbanizada", concluindo-se que ainda em 1952 se tratava de uma área agrícola possivelmente ocupada por chácaras e que não havia mais a classe "mata original na maioria dos casos devastada ou capoeirão". (Figura 2)

Na própria fotografia área de 1952 é possível perceber as nascentes principais do rio Belém em área que viria a ser ocupada pelo bairro Jardim Recanto feliz. (Figura 3).

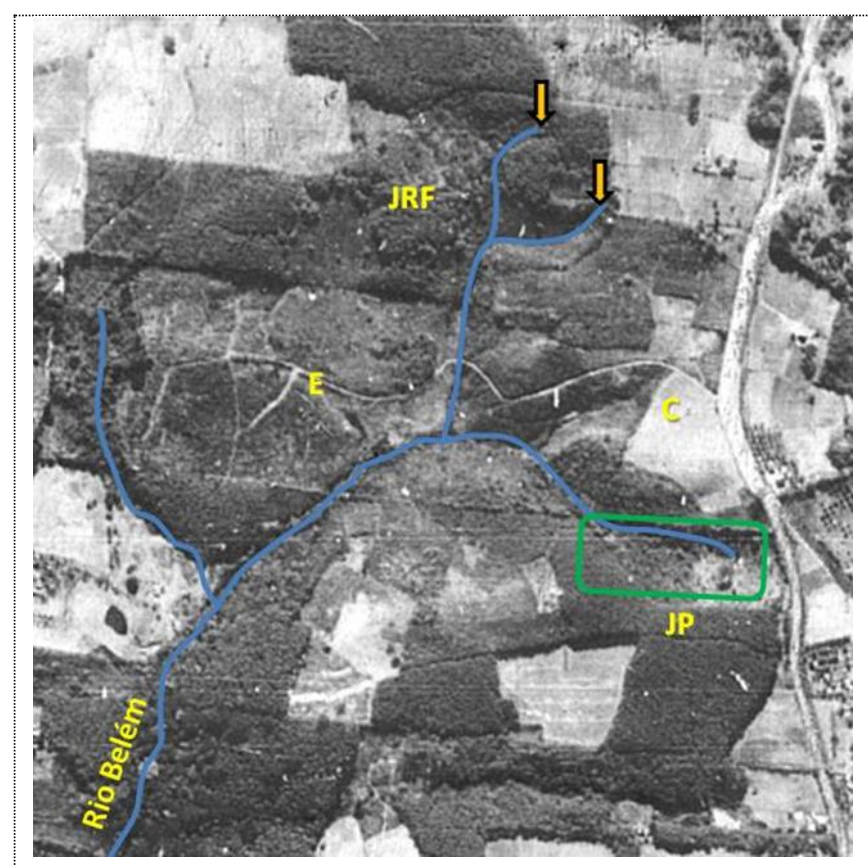

Figura 3 - Observa-se que em 1952 a área de estudo apresentava um aspecto rural. As letras em amarelo representam os locais que viriam a ser ocupados pelo bairro Jardim Recanto Feliz (JRF), Cemitério Jardim da $\mathrm{Paz}(\mathrm{C})$, área de expansão do cemitério $(\mathrm{E})$ e bairro Jardim Paulistano (JP). O retângulo com borda verde indica o local onde será implantado o Parque Municipal Nascentes do Belém. Os cursos d'água pertencentes ao rio Belém estão traçados em azul e as setas em cor laranja indicam as nascentes localizadas nas partes mais elevadas (aproximadamente $1.000 \mathrm{~m}$ em relação ao nível do mar). Fonte: Curitiba (1952). Org.: os autores, 2016.

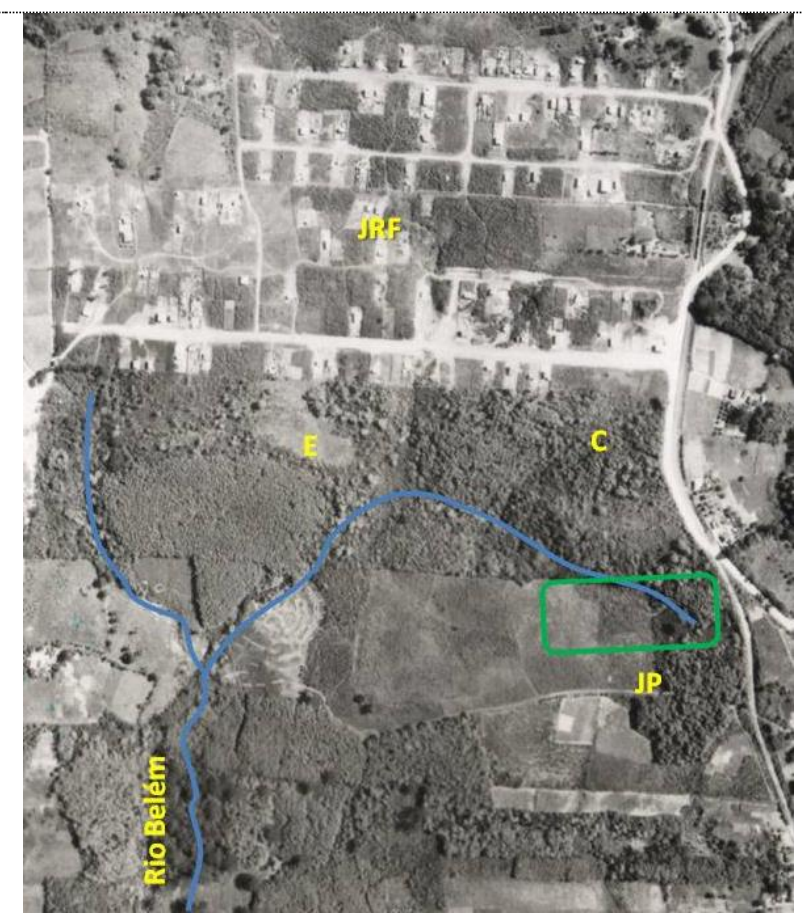

Figura 4 - Imagem com base em fotografia aérea de 1966 mostrando o traçado das ruas e a ocupação dos lotes por edificações na área que viria a ser transformar no bairro Jardim Recanto Feliz (JRF). As outras áreas permanecem com o aspecto rural. Simbologia das futuras ocupações: C (cemitério), E (área de expansão do cemitério), JP (bairro Jardim Paulistano), retângulo verde (Parque Municipal Nascentes do Belém) e a drenagem em azul. Fonte: Curitiba (1966). Org.: os autores, 2016.

Portanto, com base nas fotografias aéreas de 1952 e na Planta Fitogeográfica elaborada por Klein e Hatschbach (1962) os órgãos públicos já poderiam ter o conhecimento de que se tratava de uma área importante de nascentes do rio Belém merecedoras de proteção.

Segundo informações coletadas em entrevista realizada em junho de 2016, com a Arquiteta do setor de Planejamento do Instituto de Pesquisa em Planejamento Urbano de Curitiba (IPPUC), até o ano 2000 toda essa área era classificada como zona agrícola, e muitos dos antigos moradores possuíam chácaras com plantio de hortaliças, milho, batata, feijão, criação de porcos, ovelhas e gado. De fato, na Lei de Zoneamento de 1965 a área estava designava como zona rural e na Lei de Zoneamento de 1975 como zona agrícola e 


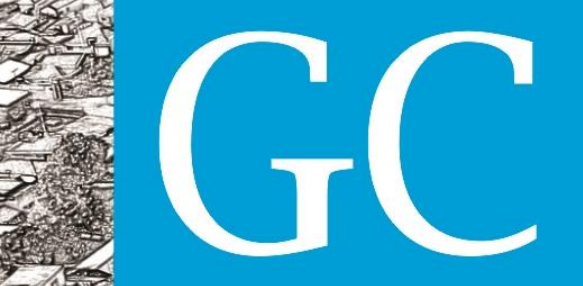

Revista Nacional de

somente com a Lei de Zoneamento de 2000 a área foi designada como zona residencial. Entretanto, na fotografia aérea de 1966 já se pode observar os primórdios da ocupação urbana na área. (Figura 4)

Comparando a figura $3 \mathrm{com}$ a figura 4, constata-se que as nascentes em maiores altitudes, visíveis na fotografia de 1952 (setas em cor laranja), se encontram desde 1966 cercadas por arruamento restando apenas, próximo a elas, uma mancha de vegetação no centro do bairro Jardim Recanto Feliz.

Também na figura 4 pode-se perceber uma mudança brusca em linha reta da textura na imagem bem no limite sul do bairro Jardim Recanto Feliz e a área pertencente ao cemitério. Portanto já em 1966 é visível o início de uma ocupação urbana em desacordo com a classificação da área que, segundo a Lei de Zoneamento de 1965 deveria ter um uso e uma ocupação rural, havendo possibilidades dos órgãos públicos responsáveis pela fiscalização e planejamento decidirem salvaguardar as áreas das nascentes do rio Belém, medidas que também poderiam estar embasadas no Código Florestal de 1965.

Com base na análise da fotografia aérea de 1972, concluiu-se que a característica rural das paisagens existentes no centro-sul da área de estudo se manteve, mas o bairro Jardim Recanto Feliz continuou a crescer. (Figura 5)

Na fotografia aérea de 1980 notou-se um avanço do arruamento do bairro Jardim Recanto Feliz por sobre as futuras áreas do cemitério. (Figura 6).

Toda a área de estudo ainda era considerada como zona agrícola, segundo a Lei de Zoneamento de 1975, e foi apenas com a implantação do Cemitério Jardim da Paz que em 1981 houve o bloqueio da expansão do bairro Jardim Recanto Feliz em direção ao sul, devido à construção de um muro separando o bairro da área do cemitério. 


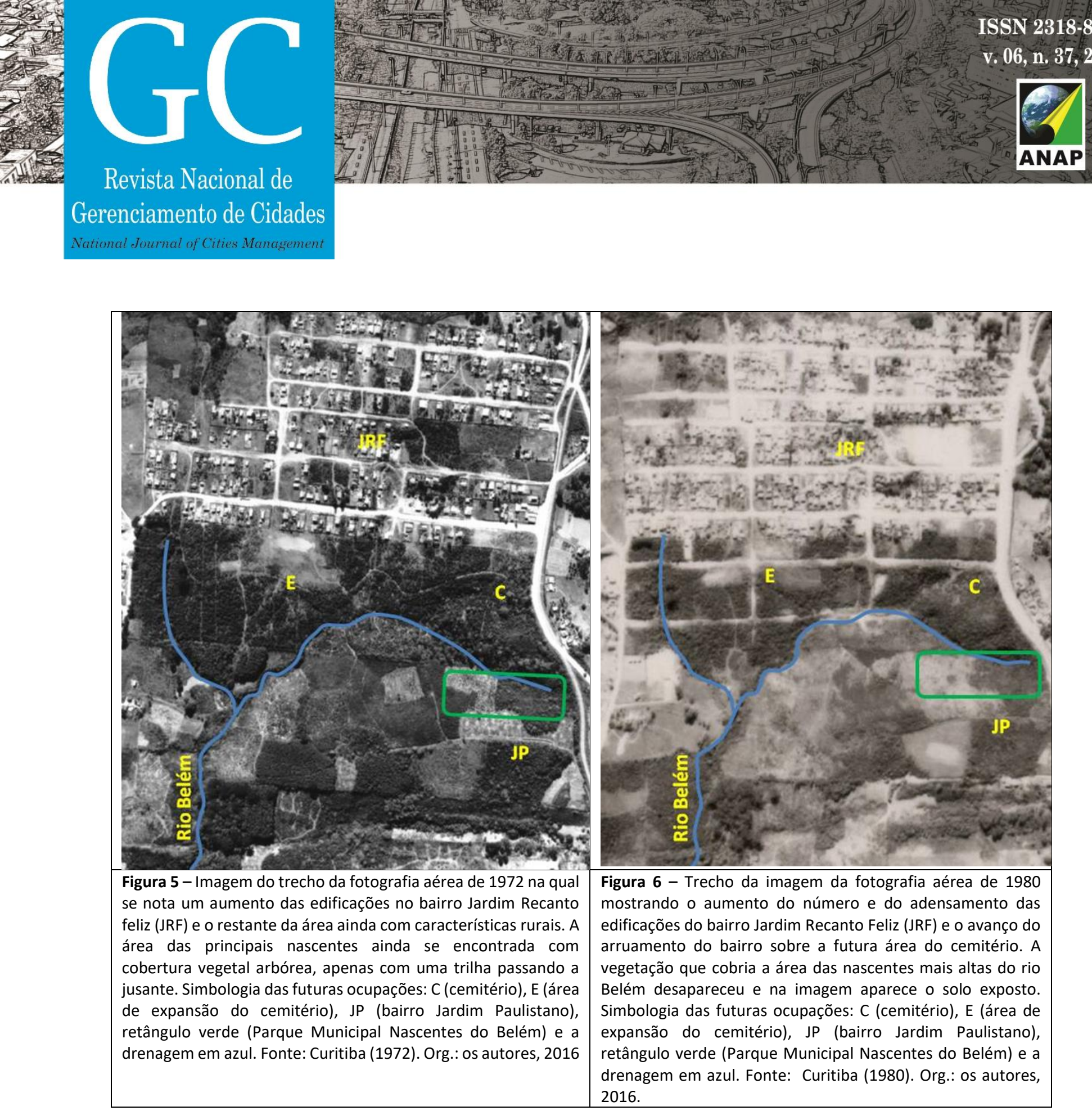

Em 1999 o bairro Jardim Recanto Feliz já se encontrava totalmente consolidado e as nascentes mais altas do rio Belém degradadas e ocupadas por edificações. O Cemitério jardim da Paz, com 18 anos de idade na época, já havia se consolidado e outras áreas ao sul do cemitério estavam sendo ocupadas por edificações, inclusive a área que viria a se transformar no Parque Municipal Nascentes do Belém, todas essas ocupações de caráter urbano ocorrendo em zona agrícola conforme a Lei de Zoneamento de 1975. (Figura 7) 
Entretanto, a Lei 9.805/2000 afirma, no seu artigo 3으, que a Secretaria Municipal do Meio Ambiente -SMMA poderá propor a inclusão, no Setor Especial do Anel de Conservação Sanitário Ambiental, de outros rios e áreas contíguas às faixas definidas no art. $2^{\circ}$, por meio de ato do Poder Executivo Municipal, o que pode vir a acontecer nessas áreas merecedoras de mais proteção.

Em entrevista, realizada em outubro de 2016 com a Coordenadora de Planejamento do IPPUC, sobre o bairro Jardim Recanto Feliz, reafirmou-se que o loteamento é mesmo clandestino. O depoimento dos moradores também revela que os proprietários das antigas chácaras transformaram suas terras em pequenos lotes, que foram vendidos para construção de casas particulares. Seguem trechos da entrevista.

\begin{abstract}
1) Como podemos caracterizar a construção de moradias no bairro Jardim Recanto Feliz?
Resposta: Pelo que eu entendi você quer saber se a ocupação é regular ou irregular? Eu tenho a informação de que ela está em regularização ainda, mas a sua origem foi um loteamento clandestino, isto é um loteamento produzido e vendido por algum loteador que, no entanto, não fez qualquer procedimento de aprovação junto a prefeitura e cartórios. Pela lei federal 6.766/79 se constitui em crime, quando há reclamações junto ao ministério público este pode abrir um processo contra o loteador. $O$ órgão responsável pela regularização de áreas ocupadas indevidamente no município é a COHAB.

2). Esta moradia tem registro de imóvel? São reconhecidas no IPPUC?

Resposta: Enquanto não houver a finalização do procedimento de regularização, isso envolve a questão documental que ali a área original é de particulares, não poderá ser feito novo registro de imóveis. Com relação ao município a partir do momento que a área entrou no cadastro municipal e está incluída nos levantamentos do plano de habitação do município e faz parte de um processo de regularização não tem como dizer que não há reconhecimento. Outra condição para o reconhecimento é o investimento em urbanização. Em relação ao planejamento a ocupação está situada em uma zona residencial de média baixa densidade e está de acordo com o planejado em termos porque as dimensões dos lotes são inferiores aos parâmetros estabelecidos.
\end{abstract}

A pouca esperança em relação a uma possível recuperação ambiental da área fica evidente quando a entrevistada declara que o bairro Jardim Recanto Feliz se encontra "de acordo com o planejado", mesmo se tratando de um bairro proveniente de "Loteamento clandestino sem regularização". Nota-se, também, que não há um planejamento articulado entre os diferentes órgãos governamentais quando a entrevistada remete a outro setor, a COHAB, a função de regularização dos loteamentos. $E$, mais uma vez, conclui-se que o monitoramento das mudanças na paisagem do município não foi eficaz, apesar da grande quantidade de material aero fotográfico disponível.

Em entrevistas com oito moradores do bairro Jardim Recanto Feliz, com faixa etária entre 43 e 68 anos, obteve-se o relato de que, há mais de 40 anos, portanto até por volta de 1975, havia um lago na parte mais baixa do morro. Neste local, a comunidade costumava pescar e também utilizava a água para lavar a lã da tosquia de ovelhas e do curtume que hoje não existem mais. Os moradores também relataram que as modificações na área foram grandes e que muitas das nascentes foram extintas.

Nas visitas a campo foram observadas nascentes brotando água dentro de várias residências, na parte mais elevada do bairro. As fotografias da figura 9 mostram uma casa de madeira construída sobre uma nascente, segundo relato de um dos moradores e em outra residência há intervenções da canalização realizada pela SANEPAR (Companhia de Saneamento do Paraná). 

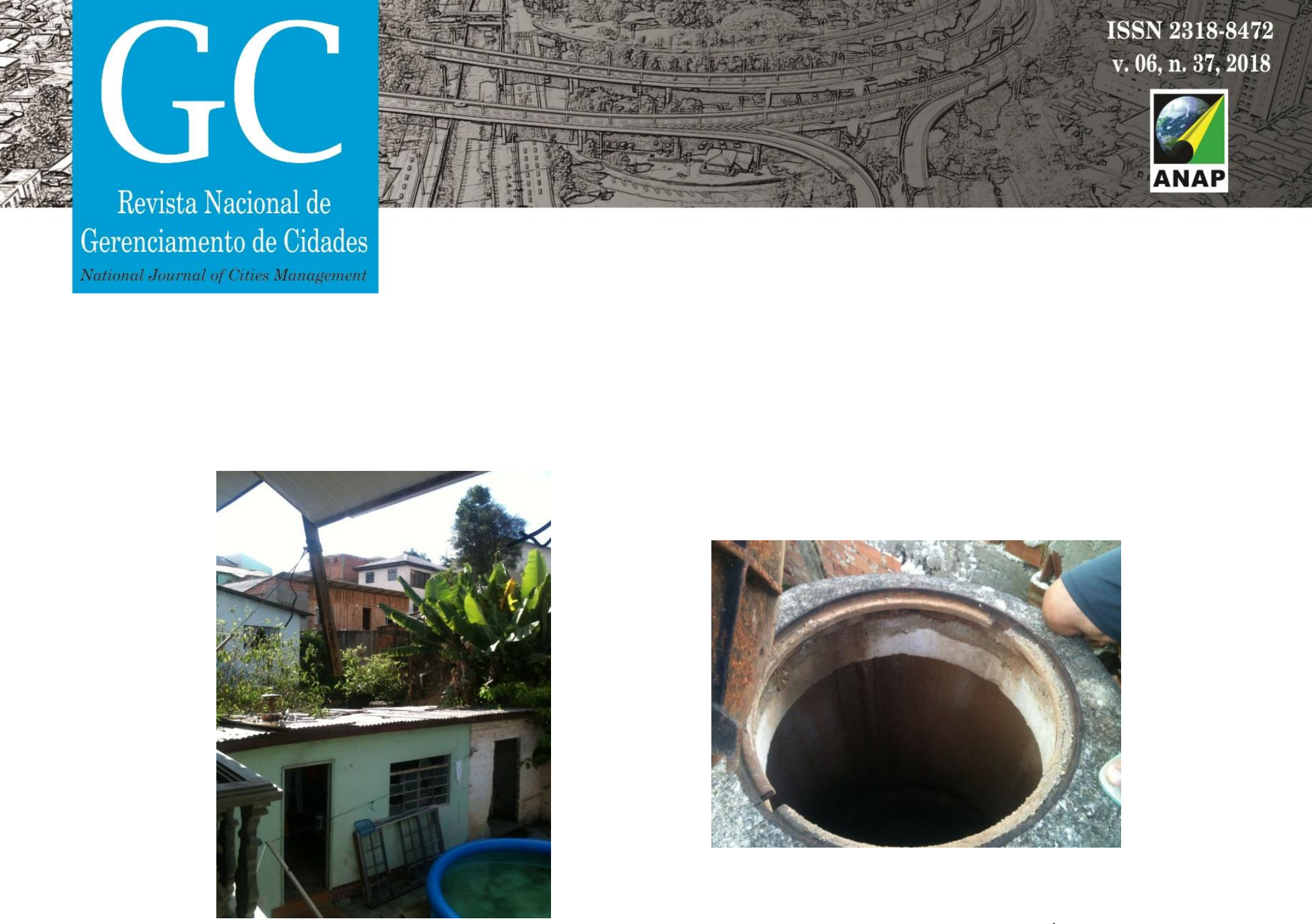

Figura 9 - Casas do bairro Jardim Recanto Feliz sobre nascentes e tubulação da SANEPAR. Fotos: Conci, J. L., março/2015.

Segundo relato dos entrevistados, a SANEPAR, a pedido dos moradores efetuou a canalização das águas das nascentes que percorriam as áreas edificadas, conduzindo-as para a rede de águas pluviais. Porém, observouse em campo que as águas das nascentes canalizadas, seguem acompanhadas pela água da chuva e pelo esgoto, e deságuam a, aproximadamente, 100 metros a jusante do Parque Municipal Nascentes do Belém, fato também constatado por Misael e Nucci (2015). Esse fato contribui para a degradação da qualidade das águas do Belém.

\section{Cemitério Jardim da Paz}

O cemitério Jardim da Paz está localizado na Av. Anita Garibaldi, 7.125, no bairro da Barreirinha, em uma vertente da margem direita do rio Belém, que drena as águas para dentro do Parque Municipal Nascentes do Belém e para a jusante do mesmo. (Figura 10) 


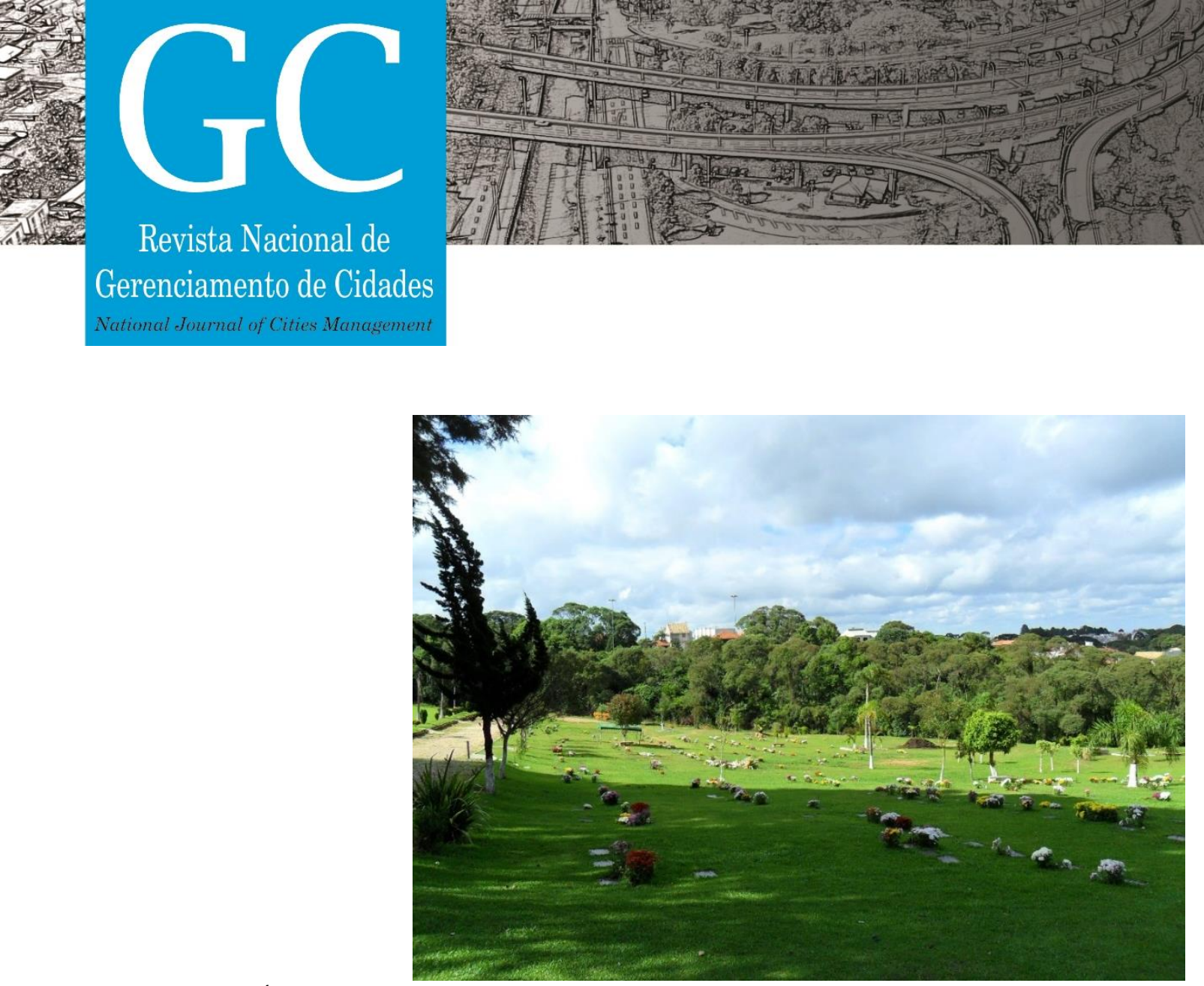

Figura 10 - Área do Cemitério Jardim da Paz. Nota-se a vertente com as lápides no primeiro plano, a mata ciliar ao longo do afluente do rio Belém que nasce dentro do Parque Municipal Nascentes do Belém e ao fundo os telhados de algumas casas do Jardim Paulistano. Foto: Conci, J.L., nov./2016.

A área total do Cemitério é de $118.000 \mathrm{~m}^{2}$, ou seja, 10 vezes maior do que a área do Parque Municipal Nascentes do Belém, abrangendo a área efetivamente implantada, uma área de expansão e parte da mata que faz divisa com o parque e a jusante do mesmo, todas essas localizadas em vertentes que drenam as águas para dentro do rio Belém.

O cemitério Jardim da Paz foi implantado em 1981, ou seja, 20 anos antes da inauguração do Parque Nascentes do Belém. Porém, o cemitério foi implantando em zona designada legalmente como agrícola pela Lei de Zoneamento de 1975 e próximo a área de nascentes que já eram consideradas como Áreas de Preservação Permanente (APPs) pelo Código Florestal de 1965.

Kemerich et al. (2016) afirmam que cemitérios são áreas que geram alterações no meio físico e por isso devem ser considerados fontes sérias de impacto ambiental negativo e que diversos estudos de natureza ambiental associam áreas que abrigam cemitérios a aterros sanitários, considerando que em ambos estão disponíveis materiais orgânicos e inorgânicos com potencial contaminante, porém, no caso de cemitérios, esses resíduos podem estar associados a um número ainda maior de patógenos, com potencial de levar à morte pessoas eventualmente contaminadas por eles. Todavia, segundo entrevista com o administrador do cemitério que, quando indagado sobre o perigo de contaminação no solo e das águas, a resposta foi que "são utilizados produtos impermeabilizantes nos jazigos, e que a cada seis meses é realizado análise da água do subsolo", afirmando que o resultado de contaminação é negativo.

Segundo Bollmann e Edwiges (2008), uma avaliação perceptiva das condições da nascente e do trecho do rio dentro do parque indicou uma boa estrutura física do corpo d'água para a colonização pelas comunidades aquáticas e um baixo índice de influência antrópica. $O$ índice de qualidade da água foi considerado como bom. Porém, os autores informam que todas essas condições pioram drasticamente logo após a saída do rio da área do parque quando este passa a receber os esgotos domésticos.

Devido ao Parque Municipal Nascente do Belém estar localizado bem ao lado de um cemitério, a população chega a afirmar que "o Belém é um rio que já nasce morto", uma crítica aos poderes públicos responsáveis em zelar pela qualidade da água desse importante rio para o município de Curitiba. 


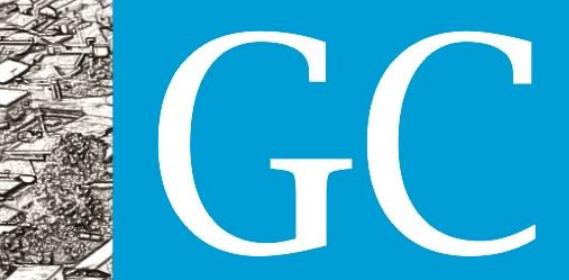

Revista Nacional de

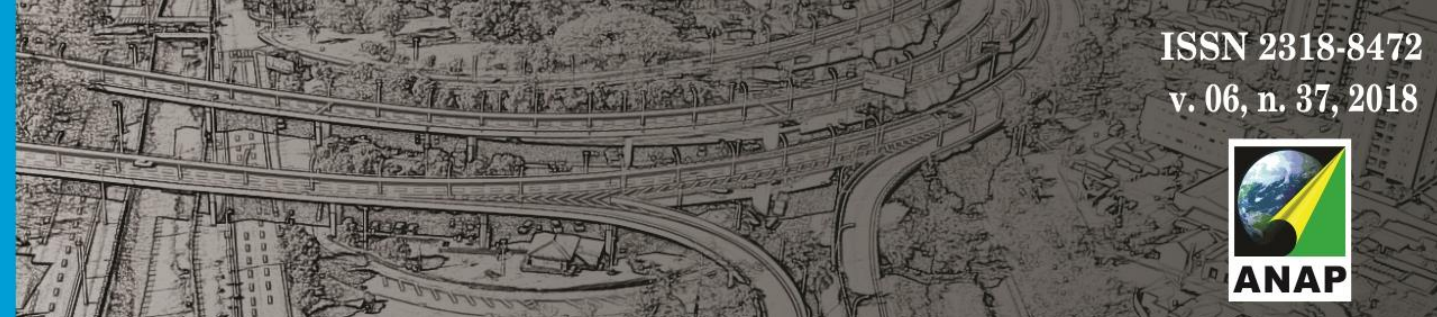

Gerenciamento de Cidades

\title{
O Parque Nascentes do Belém
}

O parque, com uma área de apenas $11.723 \mathrm{~m}^{2}$, foi criado em 24 de novembro de 2001 e, segundo a Secretaria Municipal de Meio Ambiente de Curitiba-PR, está inserido em uma proposta de recuperação de rios do município.

De acordo com uma das entrevistadas o Parque Nascentes do rio Belém foi criado por meio de um pedido da comunidade que necessitava de um espaço para recreação e para venda de trabalhos artesanais dos moradores. $O$ relato foi feito por uma moradora do bairro Jardim Recanto Feliz, de 66 anos, cujas iniciais são L. C. W., que trabalhava no Posto de Saúde da Vila Leonice, próximo ao parque:

\begin{abstract}
"Antes de ter o Parque, existia ainda uma chácara com muitas árvores, bem em frente ao cemitério. Uma construtora foi loteando e muitas pessoas compraram os lotes, mas nem todas puderam construir suas casas. Na época o Prefeito era o Taniguchi, que trabalhou junto com a gente para recuperar as nascentes e que ajudou a remanejar estas familias para outro lugar. No Parque plantaram muitas árvores e elas recuperaram a mata. O Parque foi criado a pedido da comunidade para ter um espaço para os artesãos venderem seus trabalhos manuais."
\end{abstract}

Uma outra funcionária do Posto de Saúde da Vila Leonice, M.P., de 54 anos e que também foi moradora do bairro Jardim Recanto Feliz, relata como se deu o processo de ocupação e desocupação da atual área do parque, no final da década de 1990.

"Eu morava em Almirante Tamandaré, e trabalhava no Posto de Saúde da Vila Leonice, bem em frente ao Posto era tudo mato, mata muito grande e fechada. E quando vi tinha máquinas abrindo uma rua que hoje é a rua do parque. Daí uma construtora colocou uma placa anunciando a venda de lotes ali em frente ao posto. Os lotes eram mais baratos do que os outros loteamentos por causa da caída do terreno. Meu lote era o primeiro bem na entrada onde hoje é o parque. O terreno media $16 \times 30$ metros. O valor da prestação era 700,00 reais. Quando eu comecei a construir já tinha bastantes moradores que já tinham feito suas casas. $O$ antigo loteamento se chamava Jardim Paulistano. Quando eu terminei a construção da casa em 1998, a Secretaria do Meio Ambiente notificou os moradores que a gente tinha seis meses para sair do terreno. Alegaram que ali tinha uma nascente. o morador do terceiro terreno que ficava bem em cima da nascente do atual parque, criava patos e ao cavar um buraco, percebeu que ali tinha uma nascente".

M.M.M. de 56 anos, ex- moradora de um lote onde hoje se encontra o parque, também relata que:

\begin{abstract}
"Tinha uma chácara onde hoje é o parque, e depois fizeram o loteamento, várias pessoas moravam ali com alvará da Prefeitura. Só fizeram o parque quando veio o pessoal do Meio Ambiente e viram que tinha uma casa que criava patos porque tinha um lago bem ao lado da casa dela que ficava na parte mais baixa do terreno. Foi feito uma denúncia. Tinha várias casas. Quando o Meio Ambiente veio o terreno foi embargado".
\end{abstract}

Ao afirmarem que o Parque Municipal Nascente do Belém foi criado para satisfazer a solicitação da comunidade para artesãos venderem seus trabalhos, que a área estava sendo loteada por uma construtora e já com casas sendo erguidas com alvará da Prefeitura e somente por meio de denúncia a Secretaria Municipal de Meio Ambiente em 1998 constatou a existência de uma nascente e embargou o terreno para a construção de um parque, os depoimentos deixam claro que a intenção de criação do Parque Municipal Nascentes do Belém não partiu de um modelo de planejamento sistemático, mas sim se baseou em um "modelo oportunista" (MARUANI e AMIT-COHEN, 2007), ou seja, com o aproveitamento de situações facilitadoras e já encontradas no lugar, o que serve como um exemplo pontual das constatações de Buccheri Filho (2012) para o processo de criação dos parques em Curitiba. 


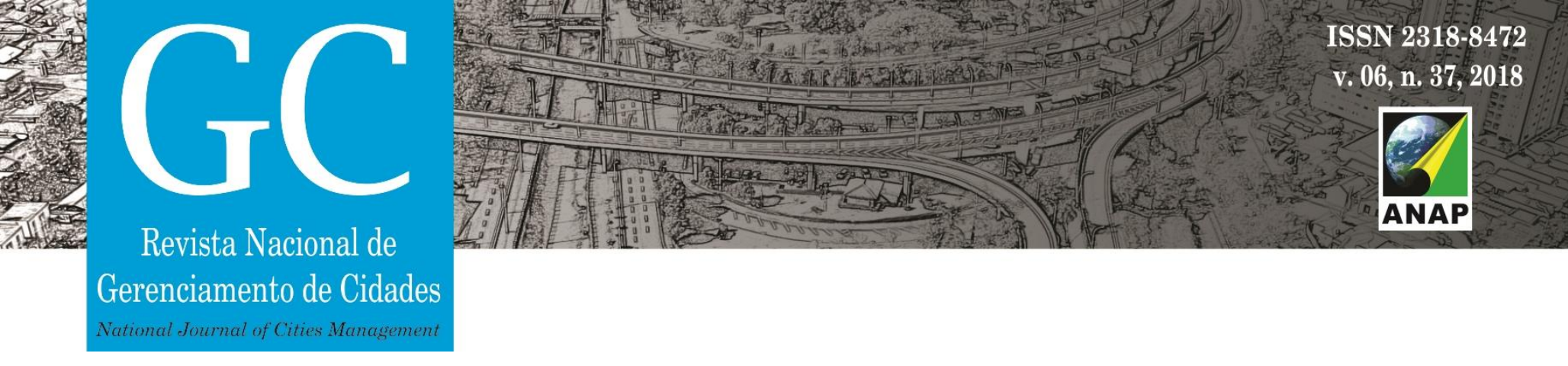

Também desses depoimentos, novamente se contata a falta de um planejamento organizado, já que um loteamento feito com permissão de parte da prefeitura é, em seguida, embargado por outro órgão da mesma prefeitura, além do inócuo monitoramento da paisagem, já que a localização das áreas do município merecedoras de proteção, como as nascentes, só é feita com base em denúncias.

\section{Cenários futuros}

Em 1999 (Figura 7) as paisagens de interesse para esta pesquisa já se encontravam consolidadas e as mudanças que surgiram nos últimos 17 anos não alteraram significativamente esses elementos principais de interesse, apenas se destaca a expansão e o adensamento das edificações no bairro Jardim Paulistano. (Figura 11)

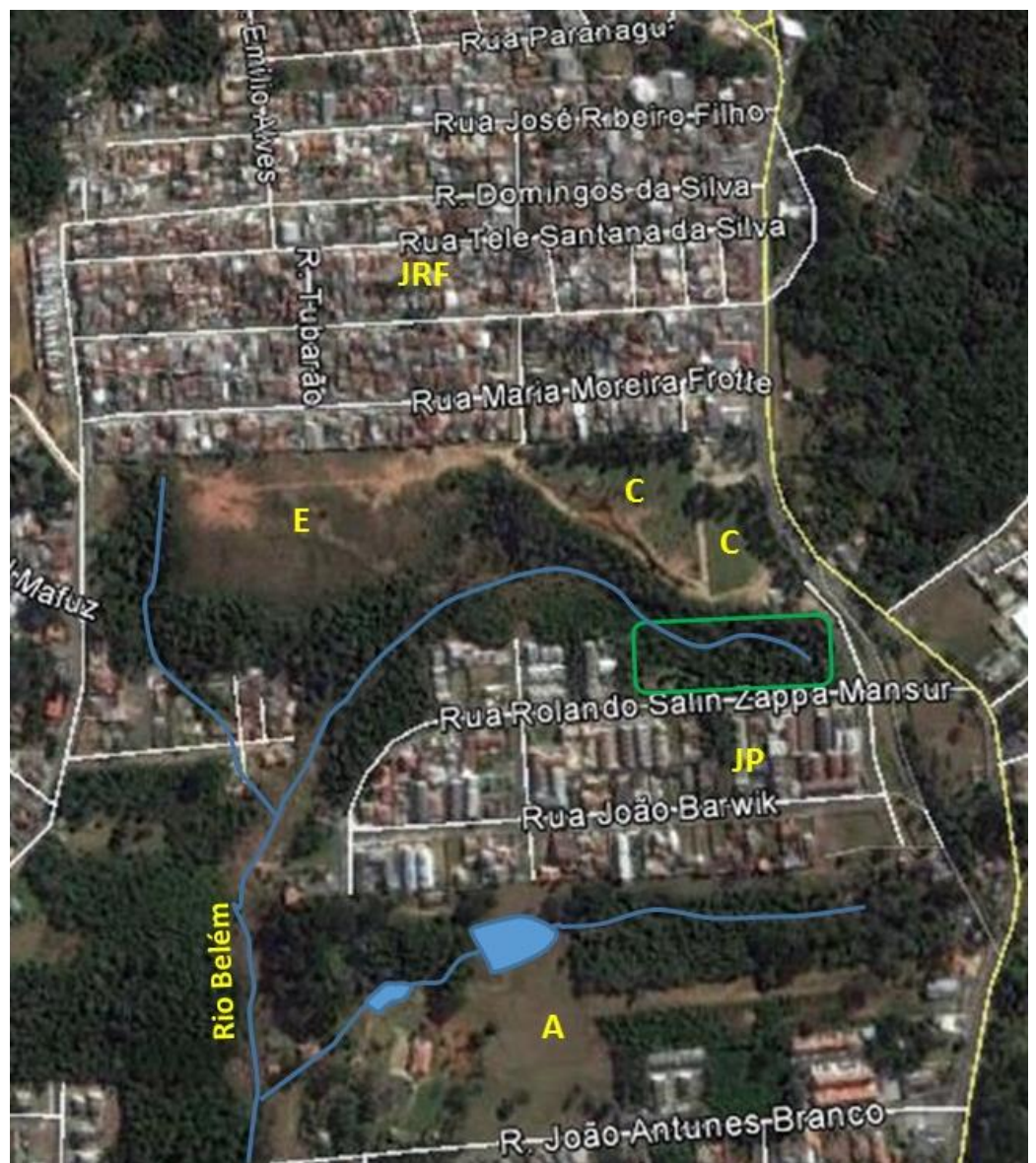

Figura 11 - Imagem fornecida pelo Google Earth, de 22/07/2016, escala aproximada 1:10.000. Simbologia: JRF (bairro Jardim Recanto Feliz), C (cemitério), E (área de expansão do cemitério), JP (bairro Jardim Paulistano), retângulo verde (Parque Municipal Nascentes do Belém), A (área com aspecto rural) e a drenagem em azul. Fonte: Google Earth (2016). Org.: os autores, 2016.

Pode-se prognosticar, pelo menos, dois cenários evolutivos dessas paisagens: cenário otimista e cenário pessimista. Os cenários foram pensados tendo como referência um bom ordenamento da paisagem visando a proteção dos recursos naturais e a utilização pela comunidade. Esses dois cenários estão descritos no quadro 1 abaixo: 
Quadro 1- Cenários de evolução da paisagem no Entorno do Parque Nascentes do Belém

\begin{tabular}{|c|c|}
\hline Cenário Otimista & Cenário Pessimista \\
\hline $\begin{array}{l}\text { - Medidas de adensamento das edificações no bairro } \\
\text { Jardim Recanto Feliz, com a construção de edifícios de até } 4 \\
\text { pavimentos e liberação e recuperação das áreas das nascentes } \\
\text { do rio Belém; todas as edificações estarão ligadas a rede de } \\
\text { esgotamento sanitário da SANEPAR e a drenagem será } \\
\text { recuperada e renaturalizada com mata ciliar original. } \\
\text { - Controle da expansão horizontal e dos gabaritos no } \\
\text { bairro Jardim Paulistano. }\end{array}$ & $\begin{array}{l}\text { - Aumento da densidade demográfica e das } \\
\text { edificações, aumento do gabarito das edificações e da } \\
\text { carga de esgoto lançada nos rios no bairro Jardim Recanto } \\
\text { Feliz. } \\
\text { - Aumento da densidade demográfica, da densidade e } \\
\text { do gabarito das edificações, e da área ocupada pelo bairro } \\
\text { Jardim Paulistano, com repercussões negativas sobre a } \\
\text { vegetação e os corpos hídricos. }\end{array}$ \\
\hline Cenário Otimista & Cenário Pessimista \\
\hline $\begin{array}{l}\text { Transformação do Cemitério Jardim da Paz em um } \\
\text { crematório, recuperando com vegetação original (Mata com } \\
\text { Araucárias), as áreas hoje ocupadas com os jazigos e } \\
\text { reflorestando com vegetação original das áreas de expansão do } \\
\text { cemitério. } \\
\text { - Aumento da área do Parque Municipal Nascentes do } \\
\text { Belém ocupando a maior parte da atual área do cemitério. } \\
\text { - Recuperação da mata ciliar de todos os corpos } \\
\text { hídricos e suas nascentes. } \\
\text { - A área com aspecto rural (letra A, na figura 11) } \\
\text { permanece como área rural e se liga aos outros corredores de } \\
\text { vegetação ciliar formando uma infraestrutura verde contínua. }\end{array}$ & $\begin{array}{l}\text { - Expansão da área ocupada pelos jazigos no cemitério } \\
\text { e contaminação do solo e dos corpos hídricos. } \\
\text { - } \quad \text { Loteamento da área ainda com aspecto rural, ao sul } \\
\text { do bairro Jardim Paulistano e surgimento de um condomínio } \\
\text { residencial murado e degradação da vegetação e dos corpos } \\
\text { hídricos e da paisagem como um todo. } \\
\text { - Morte plena do rio Belém com desmatamento da } \\
\text { vegetação ciliar de suas margens de das nascentes, aumento } \\
\text { da poluição hídrica e do assoreamento }\end{array}$ \\
\hline
\end{tabular}

\section{CONCLUSÃO}

Dos estudos sobre a evolução das paisagens do Parque Municipal Nascentes do Belém e arredores concluiuse que:

- Já no ano de 1952 não havia proteção adequada para as nascentes e cursos d'água do rio Belém devido à a ausência da Mata de Araucária na área de estudo, que se encontrava totalmente tomada por uso agrícola;

- A principal nascente do rio Belém foi soterrada com as ocupações irregulares do Bairro Jardim Recanto Feliz entre as décadas de 1960 e 1980 em área designada nas leis de zoneamento como zona rural/agrícola;

- Houve uma implantação inadequada do cemitério Jardim da Paz em 1981, por se encontrar em zona agrícola, em áreas de cabeceiras e em vertente cujas águas drenam para uma nascente de um afluente do rio Belém;

- Apesar dos sistemáticos levantamentos aerofotogramétricos realizados desde o ano de 1952 no município de Curitiba, até o ano de 1999 nada de eficiente foi feito pelos poderes públicos no sentido de barrarem as ocupações irregulares e protegerem as nascentes e cursos d'água da bacia hidrográfica do rio Belém na área de estudo, indicando uma falta de eficiência no monitoramento da evolução das paisagens do município;

- Algumas medidas paliativas dos poderes públicos foram tomadas somente no ano $2000 \mathrm{com}$ a lei que criou o Setor Especial do Anel de Conservação Sanitário Ambiental, porém no caso do rio Belém na área de estudo não houve a proteção dos $40 \mathrm{~m}$ de ambas as margens do afluente que nasce dentro do Parque Municipal Nascentes do Belém;

- No final da década de 1990 houve medidas mais severas com a desocupação de área invadida e a implantação do Parque Municipal Nascentes do Belém, porém somente devido a denúncia feita aos poderes públicos, o que demostra ineficiência em termos de fiscalização para proteção ambiental;

- Se a tendência evolutiva das paisagens entre 1952 e 1999 persistir, o cenário futuro será de degradação ambiental do que resta da vegetação e dos cursos hídricos da área de estudo, restando 


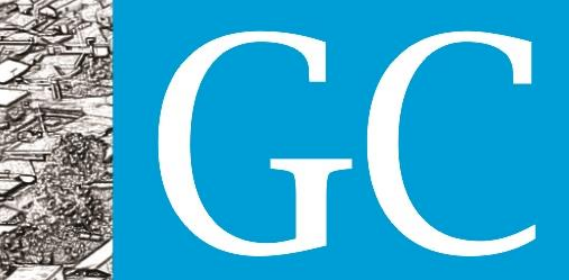

Revista Nacional de

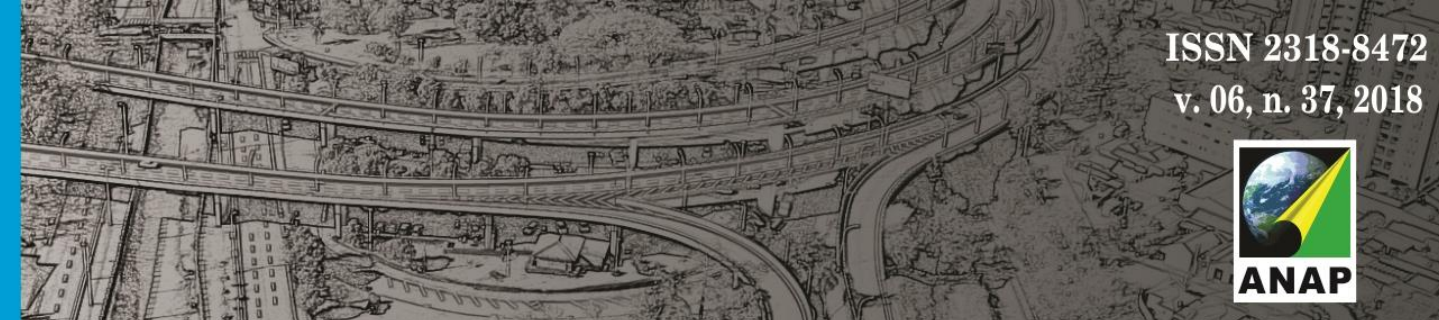

Gerenciamento de Cidades

National Journal of Cities Management

apenas o Parque Municipal Nascentes do Belém, com apenas 1 ha, com possibilidades de conservar um pouco de natureza na área de estudo.

\section{REFERÊNCIAS}

BOLLMANN, H.A. e EDWIGES, T. Avaliação da qualidade das águas do Rio Belém, Curitiba-PR, com emprego de indicadores quantitativos e perceptivos. Eng. Sanit. Ambient. V.13, n.4, Associação Brasileira de Engenharia Sanitária e Ambiental - ABES, Rio de Janeiro, 2008. Disponível em: http://www.scielo.br/scielo.php?script=sci_arttext\&pid=S141341522008000400013\&lng=pt\&nrm=iso Acesso em: 15/09/2016.

BRASIL. Lei 9.985, DE 18 DE JULHO DE 2000. Institui o Sistema Nacional de Unidades de Conservação da Natureza e dá outras providências. Disponível em: http://www.planalto.gov.br/ccivil_03/leis/L9985.htm Acesso em: 20/10/2016.

BUCCHERI FILHO, A. T. O planejamento dos parques no município de Curitiba, PR: planejamento sistemático ou planejamento baseado em um modelo oportunista? Caminhos de Geografia, Uberlândia, v. 13, n. 41, p. 206 - 222, mar/2012. Disponível em: http://www.seer.ufu.br/index.php/caminhosdegeografia/article/view/16584/9236. Acesso em: 13/11/2016.

CURITIBA. Prefeitura Municipal de Curitiba. Fotografia aérea de 1952. Escala 1:25.000. Executado por Cruzeiro do Sul S.A. Cedida pelo IPPUC.

CURITIBA. Prefeitura Municipal de Curitiba. Fotografia aérea de 1966. Cedida pelo IPPUC.

CURITIBA. Prefeitura Municipal de Curitiba. Fotografia aérea de 1972. Escala 1:12.000. Executado por EOEIG MAER. Cedida pelo IPPUC.

CURITIBA. Prefeitura Municipal de Curitiba. Fotografia aérea de 1980. Escala 1:25.000. Executado por ITC-PR. Cedida pelo IPPUC.

CURITIBA. Prefeitura Municipal de Curitiba. Fotografia aérea de 1999. Executado por ESTEIO - Engenharia e Aerolevantamentos S.A., contratada pela Prefeitura Municipal de Curitiba, coberturas aéreas de novembro/1999, dezembro/1999 e março/2000, escala efetiva de 1:2.000; resolução espacial de 0,2 metro, Datum horizontal SAD69 (original). Disponíveis em: http://ippuc.org.br/geodownloads/ortofoto/Ortofotos\%201999\%20TIFF\%20Original/Ortofotos\%201999\%20TIFF\%200riginal.html Acesso em: 16/12/12.

CURITIBA. Prefeitura Municipal de Curitiba. LEI N 9.805 de 03 de janeiro de 2000. Cria o Setor Especial do Anel de Conservação Sanitário Ambiental e dá outras providências. Disponível em: http://multimidia.curitiba.pr.gov.br/2010/00087301.pdf Acesso em: 02/01/17.

CURITIBA. Prefeitura Municipal de Curitiba. Mapa de Arruamento. IPPUC, novembro de 2015, escala 1:15.000. Disponível em: http://www.ippuc.org.br/mostrarpagina.php?pagina=350\&idioma=1\&ampliar=n\%E3o Acesso em: 11/12/2016.

CURITIBA. Prefeitura Municipal de Curitiba. Zoneamento Consolidado. Lei no 9.800/2015 - PMC/IPPUC, escala 1:20.000, dezembro de 2015. Curitiba. Disponível em: http://www.ippuc.org.br/mostrarpagina.php?pagina=352\&idioma=1\&ampliar=n\%E3o Acesso em: $17 / 12 / 16$.

CURITIBA. Prefeitura do Município de Curitiba. Mapa de Ocupações Irregulares. IPPUC, agosto de 2016, escala 1:10.000 (Fontes: Ocupações irregulares - COHAB, 2016 e Arruamento - IPPUC, 2016. Disponível em: http://www.ippuc.org.br/mostrarpagina.php?pagina=353\&idioma=1\&ampliar=n\%E3o Acesso em: 11/12/2016.

DIEGUES, Antonio Carlos Sant'ana. O Mito Moderno da Natureza Intocada. 6. ed. São Paulo: Hucitec e NUPAUB/USP, 2008. v. 1. 198 p.

FELICIO, B. C., Evolução Temporal da Legislação Ambiental e Urbanísticas das Áreas de Preservação Permanente -APPs. IV CONGRESSO BRASILEIRO DE DIREITO URBANÍSTICO. Anais $\ldots$ São Paulo. $2007 . \quad$ Disponível em: 
